\title{
The Effect of Concept Mapping on Arabic Grammar Proficiency: Al Ain University Students in the United Arab Emirates
}

\author{
Salem Khalil Al Aqtash, Omran Ahmad Musleh* \\ College of Education, Humanities and Social Sciences, Al Ain University, United Arab Emirates
}

Received May 29, 2020; Revised July 4, 2020; Accepted August 10, 2020

\begin{abstract}
Cite This Paper in the following Citation Styles
(a): [1] Salem Khalil Al Aqtash, Omran Ahmad Musleh, "The Effect of Concept Mapping on Arabic Grammar Proficiency: Al Ain University Students in the United Arab Emirates, "Universal Journal of Educational Research, Vol. 8, No. 9, pp. 4089-4096, 2020. DOI: 10.13189/ujer.2020.080934.
\end{abstract}

(b): Salem Khalil Al Aqtash, Omran Ahmad Musleh (2020). The Effect of Concept Mapping on Arabic Grammar Proficiency: Al Ain University Students in the United Arab Emirates. Universal Journal of Educational Research, 8(9), 4089-4096. DOI: 10.13189/ujer.2020.080934.

Copyright $\mathrm{C} 2020$ by authors, all rights reserved. Authors agree that this article remains permanently open access under the terms of the Creative Commons Attribution License 4.0 International License

\begin{abstract}
Concept mapping strategy is one of the vital teaching and learning strategies, due to its effectiveness for both learner and teacher. Thus, this study aimed to examine the effect of concept mapping on Arabic grammar proficiency for students at Al Ain University. The sample was comprised of students studying Arabic ( $\mathrm{n}=56$ ), who were split into an experimental group of 29 students, and a control group of 27 students. Pre- and post-tests were conducted on both groups to ensure their equivalence. The experimental group was taught six grammatical topics using concept mapping, while the control was taught the same grammar topics by the traditional method without using the concept maps. The results showed statistically significant differences between the groups, in favour of the experimental one. They also revealed statistically significant differences between the males and females in the grammar achievement test, in favour of the females. This study's results emphasize the importance of using concept mapping in teaching grammatical concepts. There is a clear compatibility between the features of concept mapping in terms of organization and logical sequence in presenting concepts on the one hand, and the nature of grammar, which is characterized by logical sequence, and hierarchical construction. The study emphasizes employing concept mapping to teach grammar on Arabic language courses at the university level, building the content of the Arabic courses according to the concept mapping strategy, and including examples of some of the
\end{abstract}

concepts mentioned in these courses so that teachers can use them.

Keywords Teaching Strategies, Concept Mapping, Teaching Grammatical Rules, Language Teaching, Grammar Concept Mapping

\section{Introduction}

As language is an essential way to obtain knowledge and make friends, how it is acquired is the subject of a great deal of research. In the Arab world, learning Arabic is essential for students because it is one of the most important components of identity for the learner in terms of listening, speaking, reading, and writing. Learning Arabic requires learning its grammatical concepts and rules, as they are the general framework on which the learner builds their understanding of the language they receive through listening and reading, and the language they produce in speaking and writing. Ashour and Al-Hawamdeh[1] indicated the importance of grammar and its relationship with the four language skills. Through listening, the learner acquires vocabulary, structures, and grammatical styles. Accordingly, one of the objectives of grammar teaching is training students to adjust their language in speech, reading, and writing in a manner that is appropriate to their 
cognitive and linguistic level. Reading exposes students to rich language, and can help them improve their vocabulary and structures. As for conversation, it is the first means of expression that satisfies a person's needs and meets their requirements in society. It is the most frequently used skill in people's lives, and the structures, styles, and patterns of language used in conversation need to be of an appropriate style, vocabulary, and refinement, and to avoid errors and slips. However, as Ahmed [2] indicated, grammatical rules are not an end in themselves, but rather a way for the learner to speak and write correctly and appropriately in a given situation.

Since Arabic grammar has multiple rules, choosing an appropriate strategy to introduce them is very important in the learning process. The concept mapping strategy has recently emerged as a result of the efforts of a number of pioneer researchers from the cognitive education school. For example, Ausubel [3] presented the meaningful verbal learning method, upon which the concept mapping strategy was based. Concept mapping was later developed as a way for learners to represent a conceptual structure as a hierarchical network diagram, with the concepts represented on a map in the form of circles or ovals, organized in levels showing the degree of extensiveness of the subject [4].

Concept mapping is appropriate to the nature of grammar and its conceptual synthesis. Al-Zoghol and Al-Bostanji [5] indicated that building thought in Arabic grammar begins with rebuilding and developing its concepts, in order to face the difficulties of learning it and acquire its concepts. This can be achieved by defining grammatical concepts and arranging them in a logical, sequential manner, so that the relationship between the concepts becomes clear. This process is in line with Al-Fatayeri [6], who stated that grammar material depends on an understanding of the logical relationships between concepts. Since learners link new knowledge to what they already know, schematic drawings of the conceptual construction of the grammar point and its concepts makes learning more meaningful. Moreover, Al-Titi [7] concurred that organizing the cognitive content of the educational material in an analytical manner is one of the most important factors facilitating the learning process, as it considers the nature, interdependence, and integration of the concepts.

With concept mapping, a learner can relate what they already know from other situations to the newly introduced concept; moreover, the symbolism of the concept itself is a way of delivering ideas and meaning to the learner [8]. Therefore, employing concept mapping as a strategy in education supports students at different academic stages, especially the tertiary stage in which a student is better able to understand abstract concepts compared to pre-university stages. On this basis, the study considers the effect of using concept mapping on the Arabic grammar proficiency of $\mathrm{Al}$ Ain University students in the United Arab Emirates.

\section{Statement of the Problem}

Being teachers of Arabic language, the researchers observed a clear weakness in their students' Arabic grammar level at various academic stages, especially at the university stage, as well as an aversion to learning and studying the subject. Dahlan [9] indicates that there are multiple reasons for a weakness in Arabic grammar, some of which are related to the nature of grammar itself. These include weaknesses related to the curriculum, students, teachers, and methods of teaching. Regarding the latter, teachers normally adopt the parroting of rules, and emphasize the memorization of examples and evidence with no analytical study; since grammatical rules are not linked with meaning, the lessons are dry, rigid and boring, and generally disliked by students [10].

Moreover, the methods of teaching grammar have an effect on determining the degree of difficulty of the subject. The problem with these methods was indicated by Al-Qarni [11], who stated that teaching Arabic grammar focuses on filling students' heads with information and terminology, such as the subject, object, accusative, and inflective, without linking them in a specific format. Another side of the problem is that the teachers think grammar is clear to them, but then find that the students express themselves unclearly, and do not differentiate between the nominative, accusative, and grammatical construction, even though they have studied these topics frequently. Thus, it is believed that there is a difficulty and rigidity in Arabic grammar due to the disintegration of the topics, and the lack of a clear link between them.

Bondoq [12] also indicated that there are clear problem areas with many grammatical concepts, causing confusion and an inability to distinguish between them, despite efforts made by teachers in this field, and emphasis on the need to use appropriate grammar teaching methods. It was therefore necessary to review common grammar teaching methods in UAE schools, since these have a clear relationship with the ease or difficulty of the grammar concept in question. Thus, if grammar is taught in a dry, automatic way that does not excite or motivate students, they leave it, but if it is taught in a modern way that raises their motivation and attracts their attention, they attend to it and love to study it [13]. In this vein, Asr [14] commented that Arabic grammar teaching methods need to be replaced, and students need a strategy derived from grammatical knowledge, if they are to learn fruitfully.

Hence, this study investigates the effect of the use of concept mapping, as a new teaching method, on the achievement levels of Arabic grammar students at Al Ain University.

\section{Research Questions}

The study poses the following questions:

- Are there statistically significant achievement scores in Arabic grammar between the experimental group 
taught using concept mapping, and the control group taught using the traditional method?

- Are there statistically significant differences in achievement scores in Arabic grammar between males and females in the sample?

\section{General Background and Previous Studies}

\subsection{Concepts and Concept Mapping}

Concepts are a key constituent of educational content, and relate to mental images formed through successive experiences. A curriculum consists of concepts that students learn in different classes, and they become more profound and abstract as the students' educational level rises [15]. Due to the importance of concepts in the learning process, how concepts are taught and presented to learners has become important for education professionals. Saadeh [16] indicated that teaching concepts helps to reduce re-learning, contributes to building a school curriculum, and facilitates the transmission of the learning effect; therefore, curriculum planners must give adequate attention to organizing concepts, by taking into consideration their degree of generality and abstraction, in a manner that is appropriate for the students' ability to form and acquire concepts at the targeted age group.

The strategy of concept mapping facilitates the teaching and presentation of concepts, by placing concepts in circles or squares and indicating their relationships by drawing lines (arrows) between them. Words can also be placed on these lines to define and clarify the relationships [17]. The philosophy and origin of concept maps is rooted in Ausubel's theory [3] known as meaningful learning. In this theory, learning is achieved by basing new knowledge on what the learner already knows, or their cognitive structure, and then reconfiguring this structure so that learning becomes meaningful. Ausubel built this theory by merging Brunner's theory on the regulation of subject matter, and Janet's theory on linking previous and subsequent learning. Ausuble assumed that a learner has a certain system for storing and preserving information, in which the classification of more general concepts and abstractions occurs by means of less general concepts and abstractions. This means that if the content is organized hierarchically in a manner appropriate to the learner's storage system, it becomes easier to retrieve [3]. Later, in 1972 at Cornell University, Novak et al. took advantage of Ausubel's theory to develop concept mapping as a teaching strategy [18-20].

\subsection{The Significance of Concept Mapping}

The importance of concept mapping is due to its role in meaningful learning. It helps learners to carry out mental processes in a more perceptive and controlled manner, and to integrate concepts within their pre-existing cognitive structure [21]. Kommers [22] noted that concept maps help students think deeply, and contribute to more effective stabilization of information in their memory; it is also a good exercise to improve creative thinking and arrive at new resolutions for problems.

The importance of concept mapping for learners was listed by Bondoq [12] as:

1. Linking new concepts/experiences to the previous concepts/experiences of the learner;

2. Establishing a hierarchical representation of relationships between concepts, from the most general to the least general;

3. Interpreting the relationships between the concepts in the curriculum;

4. Developing critical thinking skills, by searching for similarities and differences between concepts, and identifying examples that explain each concept;

5. Developing creativity and reflective thinking skills by observing mapped concepts and re-drawing them;

6. Reducing learning by memorization;

7. Developing reading comprehension skills and improving academic achievement for people with special needs.

For teachers, Bondoq [12] reported how concept maps help by:

1.

2. Planning to teach according to the semester, unit, or lesson level;

3. Helping the teaching process, as it can be used as a pre-lesson organizer, a teaching strategy during the lesson, or a late organizer at the end of the lesson;

4. Being used as a tool to evaluate learners in terms of revealing wrong perceptions and working to correct them;

5. Promoting a spirit of cooperation between teachers and learners;

6. Providing a learning atmosphere that encourages discussion between teachers and learners, and between the learners themselves;

7. Paying students' attention, and guiding them to organize their ideas.

\subsection{Building Concept Maps}

To build concept maps that achieve the required goal, it is necessary to follow a number of steps [23-25]. First, a topic is chosen for presentation as a concept map. This topic may be a lesson or a chapter. Second, the topic is analyzed, with the aim of identifying and defining its basic concepts. Third, these concepts are arranged hierarchically, from most to least general; examples and details are placed at the bottom of the map, and clarify the more general concepts above them. Fourth, the concepts are linked with 
lines showing the relationship between the concepts, and these lines are named to explain the nature of the relationship linking the concepts.

In this context, Saraya [21] and Novak and Gowin [20] referred to the role of concept maps in helping learners to perceive information that has interconnecting relationships, by facilitating the process of remembering them, providing a schematic summary of what has been learned, and directing learners' attention to the task or subject of the lesson. This can be achieved because concept maps organize concepts hierarchically. However, concept maps also help reveal the content of the learner's cognitive structure, by showing how they visualize the concepts and the hierarchical relationships that link them. They also show concepts in a simple, visual way, and increase the learner's ability to remember accurate details and examples [20]. In this regard, Hamadat and Ayasrah [26] concur that grammatical lessons using concept mapping make information easier for the learner to understand.

Many studies have dealt with the effect of using concept mapping on teaching languages. A study by Fendi and Ali [27] demonstrated the effectiveness of concept mapping in facilitating the acquisition of rhetorical concepts, and distinguishing between rhetorical concepts and their application. In their study, concept mapping helped learners to raise questions, express opinions, and participate. The results of Kalhor and Mehran's study [28] also indicated the effectiveness of concept mapping in the English proficiency of high school students, in addition to making improvements in meaningful reading comprehension and extracting key ideas from a text.

The literature also reveals that studies have been conducted on the use of concept mapping in grammar teaching and Arabic grammar teaching, and its impact on student proficiency; variously sized samples of pre-tertiary level pupils were divided into experimental and control groups, and taught with or without concept mapping, respectively. For example, Beydogan and Bayindir [29] investigated fourth grade Turkish students, and found that the experimental group had better results, specifically in understanding abstract linguistic grammar, and the interpretation of the relationships between sentences. Muqableh and Falahat [30] investigated the role of concept mapping in the Arabic grammar proficiency of 123 eighth grade male and female students in Jordan; their results showed statistically significant differences $(\alpha=0.05)$ in favour of the experimental group taught using concept mapping. In 2011, Al-Shethri [31] studied a sample of 12 non-native female students, and again there were statistically significant differences in favour of the experimental group, regarding recall, understanding, and application of grammar, as well as the retention of learning. Drawshy [24] investigated 52 male and female sixth grade students in the Northern District in Palestine, and once more there were statistically significant differences in favour of the experimental group. In Jordan, Yousef [25] studied the impact of concept mapping on the Arabic grammatical skills of 60 seventh-grade students, and again there were statistically significant differences in favour of the experimental group in terms of distinguishing between grammatical concepts and applying them in meaningful sentences.

These studies confirm the effectiveness of using concept mapping to teach Arabic grammar with pre-tertiary level students. However, although the current study shares similar objectives, to the best of our knowledge the effect of concept mapping on the Arabic grammar proficiency of university students has yet to be investigated, especially with regard to the gender variable. Thus, the study adds to the literature on employing active learning strategies in teaching Arabic grammar, in particular, and teaching concepts, in general.

\section{Methodology}

As with other studies, an experimental approach was chosen as an appropriate method to achieve the objectives. The study sample was divided into an experimental group, which was taught six grammar topics using the concept mapping strategy, and a control group, which was taught the same topics using a traditional method.

\subsection{Population}

The population of the study was Al Ain University students at Al Ain headquarters; the students were studying an Arabic course as a compulsory university requirement. The population consisted of 170 male and female students in the first semester of 2019/2020. Table 1 shows the study's population and sample percentages.

Table 1. Study Population and Sample

\begin{tabular}{|c|c|c|}
\hline Group & Number of students & Percentage \\
\hline Population & 170 & $100 \%$ \\
\hline Sample & 56 & $32.94 \%$ \\
\hline
\end{tabular}

\subsection{Sample}

The study sample of 56 male and female students studied two sections of an Arabic course (1), which is a university requirement. Table 2 shows the division of the study sample and percentage of each group.

Table 2. Description of the sample

\begin{tabular}{|c|c|c|}
\hline Section & Number of students & Percentage \\
\hline Experimental & 29 & $51.79 \%$ \\
\hline Control & 27 & $48.21 \%$ \\
\hline Total & 56 & $100 \%$ \\
\hline
\end{tabular}

The study sample was purposefully chosen, according to 
the two sections from the Arabic language course that the researchers were teaching. Section 61 was the experimental group, and Section 62 the control group. Both sections (experimental and control groups) of the course were taught by the second researcher.

\subsection{Procedure and Materials}

The study was prepared in two stages. In the initial stage, the educational material for the experimental group was prepared. First, we accessed previous studies dealing with concept mapping and reviewed procedures for preparing and employing concept mapping in teaching [25,24,31]. Then, we analyzed the set text Arabic book, from which six Arabic grammar topics were chosen for the students to learn: past and present tenses, the imperative, the subject, the nominal sentence, and annulers: kaana wa ?khwatuha (كان وأخو اتها) (kaana and its sisters), and ?inna wa ?khwatuha (إن) (?inna and its sisters). The next step was defining the basic concepts in these six topics, to identify the sub-concepts within them, and set examples to clarify both basic and sub-concepts. Concept maps were then prepared to represent these basic and sub-concepts in the form of drawings, showing linked relationships through arrows and lines. These were ordered from the most to the least general concepts, with illustrative examples placed at the end of the map. After this, the concept maps were placed on PowerPoint slides for class presentation. Figure 1 shows a concept map example for types of time verbs.

In the second preparation stage, a test consisting of 30 multiple choice questions on the six chosen subjects was created. To prepare the test, we analyzed the content of the Arabic language set text, and determined the behavioural objectives of the six topics in terms of their number and level, according to Bloom's taxonomy classifications of remembering, understanding, applying, analysing, synthesizing, and evaluating. This information was laid out in a table of test specifications, and the number of questions for each topic in the achievement test was determined. To determine the veracity of the test's content, it was presented to a number of professors of Arabic language, curricula and teaching methods, and then modifications were made to the questions based on their comments. The stability and clarity of the test was piloted with 35 male and female university students within the study population but outside the sample. The degree of stability was 7.56, which is an acceptable and appropriate percentage. Pre-testing was also undertaken to ensure the parity of the experimental and control groups, and no statistically significant differences were found between them. Table 3 shows the results of the pre-test.

The next procedural stage was to teach the groups. The teaching period lasted nine weeks, with two lectures per week of 90 minutes each. The control group was taught in the traditional way using the scheduled book, memorization, and exercises, while the experimental group was taught using the prepared material (PowerPoint slides) for concept mapping. At the start of each lesson, the teacher presented the selected concept, followed by representative examples; both the concept and examples were then discussed by the students, who proceeded to define the concept. Finally, the students were given exercises to solve from their usual textbook.

After the teaching period, a post-test was given to the two groups to reveal the differences between them, and identify the effect of the concept mapping strategy on the experimental group.

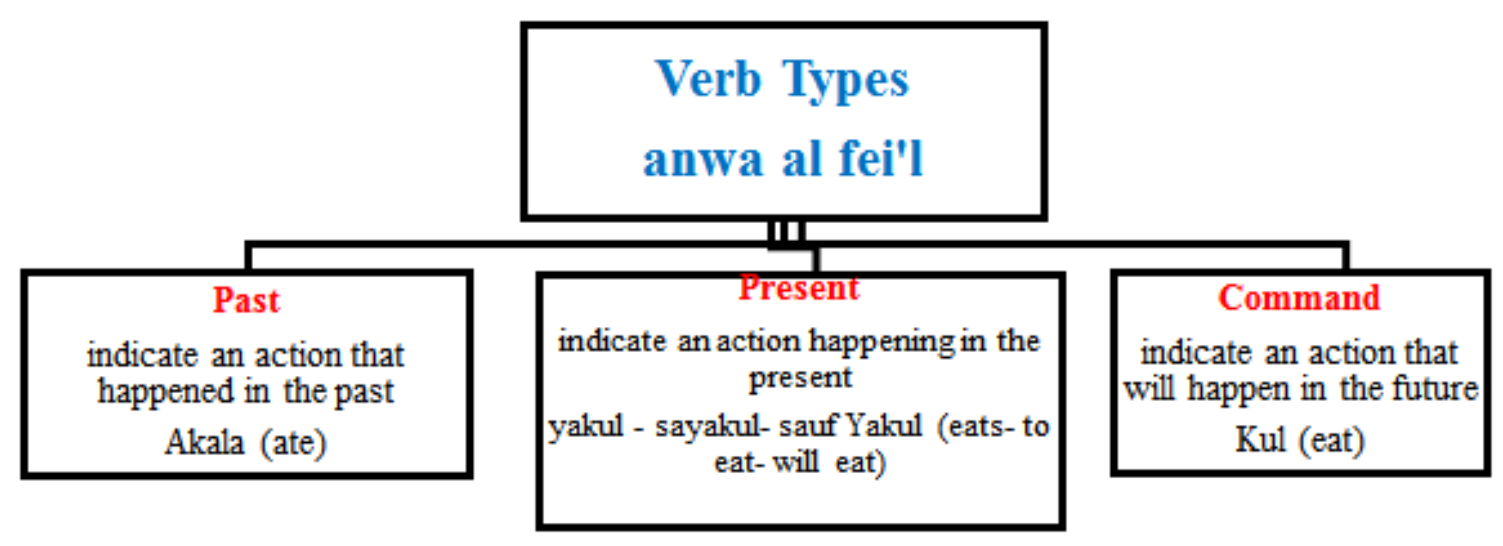

Figure 1. Verb Types in term of (Time) ${ }^{1}$

\footnotetext{
${ }^{1}$ Note that the future verb in Arabic consists of sauf + the present form, e.g. sauf yakul 'he will eat.'
} 
Table 3. Pre-test results

\begin{tabular}{|c|c|c|c|c|c|c|c|}
\hline \multirow{2}{*}{ Domain } & \multicolumn{2}{|c|}{$\begin{array}{c}\text { Experimental group } \\
\mathrm{n}=29\end{array}$} & \multicolumn{2}{|c|}{$\begin{array}{c}\text { Control group } \\
\mathrm{n}=27\end{array}$} & \multirow{2}{*}{ df } & T & Sig. (2-tailed) \\
\cline { 2 - 7 } & Mean & $\begin{array}{c}\text { Standard } \\
\text { Deviation }\end{array}$ & Mean & $\begin{array}{c}\text { Standard } \\
\text { Deviation }\end{array}$ & & \\
\hline $\begin{array}{c}\text { Overall score on } \\
\text { the achievement } \\
\text { test }\end{array}$ & 14.1034 & 5.21224 & 16.5926 & 4.65964 & 54 & -1.879 & .066 \\
\hline
\end{tabular}

Table 4. t-test results for experimental and control groups according to teaching method

\begin{tabular}{|c|c|c|c|c|c|c|c|}
\hline \multirow{3}{*}{ Domain } & \multicolumn{2}{|c|}{ Experimental group } & \multicolumn{2}{|c|}{ Control group } & \multirow{2}{*}{ df } & $\mathrm{t}$ & Sig. (2-tailed) \\
\cline { 2 - 8 } & Mean & $\begin{array}{c}\text { Standard } \\
\text { Deviation }\end{array}$ & Mean & $\begin{array}{c}\text { Standard } \\
\text { Deviation }\end{array}$ & & \\
\hline $\begin{array}{c}\text { Overall } \\
\text { score }\end{array}$ & 21.7241 & 5.02065 & 18.1111 & 4.65199 & 53.999 & 2.795 & .007 \\
\hline
\end{tabular}

Table 5. t-test results for the experimental and control groups based on gender

\begin{tabular}{|c|c|c|c|c|c|c|c|}
\hline \multirow[b]{2}{*}{ Domain } & \multicolumn{2}{|c|}{ Males $n=13$} & \multicolumn{2}{|c|}{ Females $n=43$} & \multirow[b]{2}{*}{ Df } & \multirow[b]{2}{*}{$\mathrm{t}$} & \multirow[b]{2}{*}{ Sig. (2-tailed) } \\
\hline & Mean & $\begin{array}{c}\text { Standard } \\
\text { Deviation }\end{array}$ & Mean & Standard Deviation & & & \\
\hline Overall score & 16.3077 & 4.06990 & 21.0930 & 4.93681 & 23.710 & -3.527 & .002 \\
\hline
\end{tabular}

\subsection{Data Analysis}

An independent sample t-test was conducted to determine the equivalency of the experimental and control groups two groups in the pre-test, and the same test was repeated after the intervention to find the statistical differences between the males and females. Mean, standard deviation, and $t$ and $p$ - values were therefore calculated.

\section{Results and Discussion}

The first question of the study concerned whether there would be statistically significant differences in the post-test Arabic grammar proficiency between the experimental and control groups. Table 4 shows the results of the two groups.

As shown in Table 4, there were statistically significant differences between the experimental and control groups in the post-test, in favour of the experimental group taught grammar using concept mapping. The arithmetical mean of the experimental group was 21.7 , with a standard deviation of 5.02. In contrast, the arithmetical mean of the control group taught using the traditional method was 18.11 (standard deviation 4.65). The comparatively better performance of the experimental group over the control may have been due to the advantage of presenting the grammatical concepts via concept mapping, in terms of organization and logical sequence. Concept maps help to present the topics in an attractive way, while the logical sequence in building grammatical knowledge helps understanding of the grammatical concepts. These may therefore have been integrated into the cognitive structure of students and their previous experiences, and perhaps enabled their retention. This is in line with Saraya [21] and Novak and Gowin [20], who referred to the role of concept mapping in helping learners determine the relationships between sets of information, facilitating the process of remembering them, providing a planning summary of what has been learned, and drawing attention to the subject of the lesson. Therefore, concept maps work to organize concepts in a hierarchical manner.

Moreover, since grammar topics are characterized by a degree of abstraction, it may be that identifying the logical links between them makes concept mapping an appropriate and effective method of teaching, easing the difficulty that grammar represents for many students. This is in line with Al-Zoghol and Al-Bostanji [5] who indicated that building thought in Arabic grammar begins by rebuilding and developing its concepts, and arranging them in a logical and sequential manner to facilitate learning. The results of the current study are also consistent with those of other studies on grammar teaching $[24,25,29,30,31]$.

The second question of the study concerned whether there would be statistically significant differences in the Arabic grammar proficiency of the sampled students based on gender. Again, a t-test was repeated for the two groups according to the different method of teaching. Table 5 shows the differences between the males and females.

As shown in Table 5, there were statistically significant differences between the proficiency in Arabic grammar of the male and female $\mathrm{Al}$ Ain University students, in favour of the females (mean 21.09, standard deviation 4.93; males mean 16.30, standard deviation 4.07). The reason why the female group scored more highly than the males on achievement may be due to a sense of challenge among the female students, and a desire to prove themselves and obtain a university degree, especially in the presence of family burdens on girls in the UAE. Another reason may be that the female students have more time to study than males, 
who spend most of their time outside the home, at work or with friends. The female students took the test very seriously, unlike the males, who took the test for the sake of the awarded mark. The results of the current study regarding female students are consistent with those of Milad [23], which also found that the female students scored more highly than the males in post-test results.

\section{Conclusions and Recommendations}

This study's results emphasize the importance of using concept mapping in grammar teaching, especially Arabic grammar, and the grammatical concepts therein. There is a clear compatibility between the features of concept mapping in terms of organization and logical sequence in presenting concepts on the one hand, and the nature of grammar, which is characterized by interdependence, logical sequence, and hierarchical construction. This makes concept mapping an effective strategy for teaching and presenting grammar concepts to students. It is possible that concept mapping may even change students' impression of grammar as a hard and rigid subject to an attractive, easy to understand one. According to the results of the study, the researchers recommend:

1. Using concept maps to teach grammatical concepts in the Arabic course taught to Al Ain University students;

2. Being able to teach and use concept maps on Arabic courses that contain many concepts, such as rhetoric, morphology, e.g. Altakhaineh [32, 33], spelling, and others;

3. Building the content of the Arabic courses according to the concept mapping strategy, and including examples of some of the concepts mentioned in these courses so that teachers can use them.

\section{REFERENCES}

[1] Ashour, Ratib and Hawamdeh, Mohamed Fouad. Arts of the Arabic language and its teaching methods between theory and practice. The modern world of books. Irbid. Jadara for the International Book, Amman, 2009.

[2] Ahmed, Muhammad, Methods of teaching Arabic. 6th Edition, The Egyptian Renaissance Library. (Maktabt AlNahda AlMisryya), 1979.

[3] Ausubel, David. P. Educational psychology: A cognitive View. New York Holt, Rinehart and Winston, Inc, 1968.

[4] Al-Zoubi, Talal. The relationship between the use of the conceptual mapping strategy in teaching curricula for research in education and psychology for education diploma students and their acquisition of scientific research skills and their achievement of concepts. Dirasat Educational Sciences, university of Jordan. Volume: 30, N: 2, 369-385, 2003.
[5] Al-Zoghol, Rafe'. \& AL-Bostanji, Waheed. The Impact of the Hierarchy organization of Arabic Grammar on Immediate and Delayed achievement of Eighth Grade Students in Jordan. Mu'tah for Research and Studies, 22 (4), 77-96, 2007.

[6] Al-Fatayeri, Sami Mohamed, The effectiveness of metacognitive strategy in developing the skill of reading text and philosophical attitudes at the secondary stage, Journal of the Faculty of Education Zagazig University. N: 27, Part One, pp. 225-255, 1996.

[7] Al-Titi, Mohamed. Cognitive structure to acquire concepts: learning and teaching. House of Hope. Irbid, 2004.

[8] Khader, Fakhri Rashid. Methods of Teaching Social Studies. 2nd edition, Dar Al Massira for Publishing, Printing \& Distribution, Amman: Jordan, 2014.

[9] Dahlan, Omar Ali. The effect of advanced organizers on the students of the 8th grade achievement and retention at Arabic grammar. Unpublished Master Thesis, Islamic University of Gaza, Palestine, 2003.

[10] Al-Hashemi, Abid. The practical guide for the Arabic teacher. 3th edition, Beirut: Resalah Foundation, 1983.

[11] Al-Qarni, Saliha Muhammad Zafer. level of Arabic language teachers' ability in developing grammatical skills among third secondary school students in the Holy Capital, unpublished Master Thesis, College of Education, Umm Al Qura University: Makkah Al-Mukarramah, 2010.

[12] Bondoq, Sarah Samir Abdel-Fattah. A suggested scenario for teaching some morphological derivatives using concept maps of prep pupils, Journal of the Faculty of Education, Port Said University, No. 15- January 2014, 535-552, 2014.

[13] Hajjo, Jacob. The effect of cooperative learning method on the achievement of the ninth grade students in the Arabic grammar in Gaza Governorate, unpublished Master Thesis, Islamic University of Gaza, Palestine, 1999.

[14] Asr, Hosni Abdel Bari. Skills of teaching Arabic grammar: theory and practice. Alexandria Book Center. Alexandria, 2005.

[15] Marie, Tawfiq Ahmed; and Al-Hela, Muhammad Mahmoud. Modern educational curricula: concepts, elements, foundations, and processes. 13th edition, Dar Al Massira for Publishing, Printing \& Distribution, Amman: Jordan, 2016.

[16] Saadeh, Jawdat Ahmad; and Abdullah, Mohmmad Ibrahim. Curriculum Models, Planning and Development. Dar El Shorouk for Publishing and Distribution, Amman, 2001.

[17] Novak, J. D. \& Cañas, A. J. The Theory Underlying Concept Maps and How to Construct Them, 2015. Research gate: retrieved from internet on:09/07/2019: https://www.researc hgate.net/publication/252642478_The_Theory_Underlying _Concept_Maps_and_How_to_Construct_Them.

[18] Vanhear, Jacqueline. and Johnston, Christine. Vee Heuristics, Concept Mapping and Learning Patterns: merging Meta cognitive tools and learning processes to improve facilitation of learning with primary school children. Conference: Second International Conference on Concept Mapping at: San Jose, Costa Rica 2006. Retrieved from 
internet on 27/1/2020: https://www.researchgate.net/publica tion/270285003_VEE_HEURISTICS_CONCEPT_MAPPI NG_AND_LEARNING_PATTERNS_MERGING_META COḠNITIVEE TOOLS AND LEARNING PROCESSES TO_IMPROVE_FACILITATION_OF_LEARNING_WIT H_PRIMARY $\bar{C}$ HILDREN

[19] Novak, J. D. \& Cañas, A. J. Theoretical origins of concept maps, how to construct them and uses in education. Reflecting Education, 3(1), 29- 42, 2007.

[20] Novak, Joseph. \& Gowin, Bob. Learning how to learn. translation: Ahmed Safadi, Ibrahim AL-Shafei. Riyadh: King Saud University Press, 1995.

[21] Saraya, Adel. Instructional Design and Meaningful Learning: A Conceptual Application View in the Light of Information Processing Theory in Human Memory. Amman. Dar Wael, 2007.

[22] Kommers, P.A. Cognitive support for learning: Imagining the Unknown. Nieuwe Hemweg 6B 1013 BG Amsterdam: IOS Press. 2004. Retrieved from: on 10/07/2019 https://books.google.ae/books?id=gbIApTr4viYC\&printsec $=$ frontcover\&dq=Cognitive+support+for+learning:+Imagin ing + the + Unknown\&hl $=$ en $\&$ sa $=$ X\&ved $=0$ ahUKEwiu e3di6njAhUWSRUIHROTDOkQ6AEIKDAA\#v=onepage $\& q=$ Cognitive $\% 20$ support $\% 20$ for $\% 20$ learning\%3A\%20Im agining $\% 20$ the $\% 20$ Unknown\&f $=$ false

[23] Milad, Reem Alajaili Saleh. The effect of using concept mapping strategy on academic achievement in subject of Islamic Education among the seventh graders of primary school students at Libyan schools in KL, Malaysia, unpublished master thesis, Al-Madinah International University, Malaysia, 2018.

[24] Drawshy, Hasan. Concept maps and their impact on academic achievement in syntax among sixth graders in an Arab primary school in Northern Israel. Project submitted to the graduate learning Master Degree in: Teaching and Learning, Alqasmi collage of education-M.E.d, 2016.
[25] Yousef, Afaf. The effect of concept mapping strategy on improving grammar skills among seventh grade male students in Irbid Directorate, An-Najah University Journal for Research-B (Humanities), Volume 33 (1), 103-124, 2019.

[26] Hamadat, Muhammad Hassan, and Ayasrah, Muhammad. Conceptual maps in grammatical, morphological, and spelling rules, Dar Al-Hamed, Amman: Jordan, 2011.

[27] Fendi, Asmaa Kazem. and Ali, Iman Hassan. The impact of using concept maps on acquiring rhetorical concepts among Students in the Preparatory Stage. Al-Fath, Journal, N: 50, 1- 46, 2012.

[28] Kalhor, M. \& Mehran, G. The Effect of Concept Mapping on EFL Students' Meaningful Learning of English Reading Comprehension. Innovating with Concept Mapping Proc. of the Seventh Int. Conference on Concept Mapping, Tallinn, Estonia 2016.

[29] Beydogan, H.O. \& Bayindir, G.B. Effect of concept map supported teaching approaches from rules to sample and sample to rules to grammar teaching, Procedia- Social and Behavioral Sciences, 2, 354 - 364, 2010.

[30] Muqableh, Nasr Muhammad Khalifa, and Al Falahat, Ghassaib Muhammad Mutlaq. The Impact of Teaching Using Conceptual Maps on the Achievement of Eighth Grade Students of Arabic Grammar in Jordan, University of Damascus Journal, 26 (4), 559 590, 2010.

[31] Al-Shethri, Najlaa bint Ibrahim. The Effectiveness of Using Concept plans in Teaching Grammar for Non-Arabic Speaking Students, Unpublished Master Thesis, Imam Muhammad ibn Saud Islamic University, 2011.

[32] Altakhaineh, Abdel Rahman Mitib. Identifying $\mathrm{N}+\mathrm{N}$ compounding in modern standard Arabic and Jordanian Arabic. Studia Linguistica 73 (1), 1-36, 2019.

[33] Altakhaineh, Abdel Rahman Mitib. Identifying Arabic compounds other than the Synthetic Genitive Construction. Acta Linguistica Hungarica, 63 (3), 277-298, 2016. 